\title{
Association between Selective Serotonin Reuptake Inhibitors Use and Colorectal Cancer in a Case- Control Study
}

\author{
Shih-Wei Lai ${ }^{1,2}$, Cheng-Li Lin ${ }^{1,3}$, Kuan-Fu Liao, 4,5, \\ ${ }^{1}$ Department of Family Medicine, College of Medicine, China Medical University, Taichung, TAIWAN. \\ ${ }^{2}$ Department of Family Medicine, China Medical University Hospital, Taichung, TAIWAN. \\ ${ }^{3}$ Department of Management Office for Health Data, China Medical University Hospital, Taichung, TAIWAN. \\ ${ }^{4}$ Department of Internal Medicine,College of Medicine, Tzu Chi University, Hualien, TAIWAN. \\ ${ }^{5}$ Department of Hepatogastroenterology, Department of Internal Medicine, Taichung Tzu Chi Hospital, Taichung, TAIWAN.
}

\begin{abstract}
Objectives: This study's aim was to investigate whether selective serotonin reuptake inhibitors use was associated with the risk of colorectal cancer. Methods: From the claims data of Taiwan National Health Insurance Program, a retrospective case-control study was conducted to examine 4739 aged $20-84$ cases with newly diagnosed colorectal cancer in 2000-2013 and 4739 sex-matched and age-matched controls without colorectal cancer. The prescription history of selective serotonin reuptake inhibitors and other comorbidities were compared between the cases and the matched controls. Results: After adjusting for the potential confounders, the multivariable logistic regression model showed that the odds of selective serotonin reuptake inhibitors use among cases with colorectal cancer were lower than the odds of selective serotonin reuptake inhibitors use among matched controls (adjusted OR 0.77; $95 \% \mathrm{Cl}$ 0.66-0.89). Conclusion: The odds of selective serotonin reuptake inhibitors use among cases with colorectal cancer are lower than among matched controls. This finding indicates that selective serotonin reuptake inhibitors use might be a protective factor against colorectal cancer.
\end{abstract}

Key words: Case-control study, Colorectal cancer, Selective serotonin reuptake inhibitors, Taiwan National Health Insurance Program.

\section{INTRODUCTION}

Selective serotonin reuptake inhibitors are widely used to treat depression. ${ }^{1,2}$ Animal studies have shown that selective serotonin reuptake inhibitors possess potential anti-proliferative effects on tumor cells and further inhibit the growth of colorectal tumor. ${ }^{3,4}$ However, epidemiologic studies showed controversial results. Three retrospective case-control studies showed that selective serotonin reuptake inhibitors use was significantly associated with 30\%-53\% risk reduction of colorectal cancer, ${ }^{5-7}$ but other studies did not detect a significant association between selective serotonin reuptake inhibitors use and colorectal cancer. ${ }^{8,9} \mathrm{~A}$ meta-analysis by Lee and colleagues also did not detect a significant association. ${ }^{10}$

Colorectal cancer was the third leading cause of cancer death in Taiwan in 2016. ${ }^{11}$ There were $5722(12 \%)$ case deaths due to colorectal cancer among 47760 total cancer deaths. ${ }^{11}$ To date, no definite report is available on the association between selective serotonin reuptake inhibitors use and colorectal cancer in Taiwan. Therefore, we conducted a case-control study to investigate whether selective serotonin reuptake inhibitors use was associated with the risk of colorectal cancer.
Submission Date: 09-07-2018; Revision Date: 14-08-2018; Accepted Date: 18-01-2019

DOI: 10.5530/ijper.53.2.41

Correspondence: Dr. Kuan-Fu Liao, Department of Hepatogastroenterology, Department of Internal Medicine, Taichung Tzu Chi Hospital, No.66, Sec. 1, Fongsing

Road, Tanzi District, Taichung City, 427, TAIWAN. Phone: 886-4-3606-0666 E-mail: kuanfuliaog@gmail. com

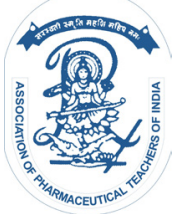

www.ijper.org 


\section{MATERIALS AND METHODS}

\section{Study design and data source}

We conducted a case-control study utilizing the claims data of Taiwan National Health Insurance Program. The program was launched in March 1, 1995 and it has covered about $99.6 \%$ of 23 million people living on an independent country of Taiwan. ${ }^{12-14}$ The details of the program were well documented in previous studies. ${ }^{15-17}$

\section{Study subjects}

Based on International Classification of Diseases $9^{\text {th }}$ Revision-Clinical Modification (ICD-9 codes), we selected 4739 aged 20-84 subjects with newly diagnosed colorectal cancer in 2000-2013 as the cases (ICD-9 codes 153 and 154). For each case with colorectal cancer, we randomly selected one subject without colorectal cancer as the matched control. The cases and the matched controls were frequency matched with sex, age (every 5-year interval) comorbidities and the year of the index date. The date of a case being diagnosed with colorectal cancer was defined as the index date. To reduce the biased results, subjects with any other cancer before the index date were excluded.

\section{Comorbidities studied}

Comorbidities before the index date were selected as follows: alcohol-related disease, cardiovascular disease, chronic kidney disease, chronic liver disease, chronic obstructive pulmonary disease, colorectal adenoma, diabetes mellitus, hyperlipidemia, hypertension, as well as inflammatory bowel disease. All comorbidities were identified based on ICD-9 codes, which has been validated in previous studies. ${ }^{18-20}$

\section{Definition of drug exposure}

We collected the prescription histories of selective serotonin reuptake inhibitors and other anti-depression drugs. In Taiwan, the group of selective serotonin reuptake inhibitors during 2000-2013 included fluoxetine, fluvoxamine, paroxetine, sertraline, citalopram and escitalopram. The definition of drug exposure was depicted in previous studies. ${ }^{21-23}$ Subjects who ever had a prescription for drugs studied were defined as ever use. Subjects who never had a prescription for drugs studied were defined as never use.

\section{Statistical analysis}

The Chi-square test and the $t$-test were used to examine the differences of demographic status, drugs use and comorbidities between the cases and the matched controls. Variables which were found to be significantly associated with colorectal cancer in a univariable logistic regression model were further included in a multivariable logistic regression model. The odds ratio (OR) and 95\% confidence interval (CI) were used to estimate the odds of selective serotonin reuptake inhibitors use among cases with colorectal cancer and matched controls. Last, we performed an analysis about the duration-dependent effect of selective serotonin reuptake inhibitors use on the risk of colorectal cancer. The probability value < 0.05 was considered statistically significant (SAS software version 9.2, SAS Institute Inc., Cary, North Carolina, USA).

\section{RESULTS}

\section{Characteristics of the study population}

Table 1 shows 4739 cases with colorectal cancer and 4739 matched controls without colorectal cancer. The cases and the matched controls had a similar distribution of sex. The mean ages (standard deviation) were 63.8(12.7) years in cases and $63.1(12.8)$ years in matched controls, with statistical significance ( $t$-test, $P=0.01$ ). The matched controls had a higher proportion of ever use of selective serotonin reuptake inhibitors than the cases, with statistical significance $(8.59 \%$ vs. $6.79 \%$, Chi-square test, $P=0.001)$. There were no statistic differences of other anti-depression drugs and comorbidities between the cases and the matched controls (Chi-square test, $P>0.05$ for all), except inflammatory bowel disease.

\section{Association between colorectal cancer and selective serotonin reuptake inhibitors use}

Variables which were found to be significantly associated with colorectal cancer in a univariable logistic regression model were further included in a multivariable logistic regression model. Only sex and inflammatory bowel disease were compatible with the analysis criteria. The multivariable logistic regression model showed that the odds of selective serotonin reuptake inhibitors use among cases with colorectal cancer were lower than the odds of selective serotonin reuptake inhibitors use among matched controls (adjusted OR 0.77; 95\% CI 0.66-0.89, Table 2).

\section{Association between colorectal cancer and cumulative duration of selective serotonin reuptake inhibitors use}

Table 3 shows that the odds of cumulative duration of selective serotonin reuptake inhibitors use $<12$ months among cases with colorectal cancer were lower than among matched controls (adjusted OR 0.80; 95\% CI 0.67-0.95). The odds of cumulative duration of selective serotonin reuptake inhibitors use $\geq 12$ months among 
Table 1: Characteristics between cases with colorectal cancer and matched controls

\begin{tabular}{|c|c|c|c|c|c|}
\hline \multirow[b]{2}{*}{ Variable } & \multicolumn{2}{|c|}{$\begin{array}{l}\text { Matched controls } \\
\quad \mathrm{N}=4739\end{array}$} & \multicolumn{2}{|c|}{$\begin{array}{l}\text { Cases with colorectal cancer } \\
\qquad \mathrm{N}=4739\end{array}$} & \multirow[b]{2}{*}{$P$ value } \\
\hline & $\mathbf{n}$ & $(\%)$ & $\mathbf{n}$ & (\%) & \\
\hline Sex & & & & & 0.92 \\
\hline Female & 2018 & $(42.6)$ & 2023 & $(42.7)$ & \\
\hline Male & 2721 & $(57.4)$ & 2716 & $(57.3)$ & \\
\hline Age group (years) & & & & & 0.12 \\
\hline 20-39 & 217 & $(4.5)$ & 213 & $(4.4)$ & \\
\hline $40-64$ & 2245 & $(47.4)$ & 2149 & $(45.4)$ & \\
\hline $65-84$ & 2277 & $(48.1)$ & 2377 & $(50.2)$ & \\
\hline Age (years), mean \pm standard deviation ${ }^{\dagger}$ & \multicolumn{2}{|c|}{$63.1 \pm 12.8$} & \multicolumn{2}{|c|}{$63.8 \pm 12.7$} & 0.01 \\
\hline Ever use of selective serotonin reuptake inhibitors use & 407 & $(8.59)$ & 322 & $(6.79)$ & 0.001 \\
\hline Ever use of other antidepressants & 1237 & $(26.1)$ & 1183 & $(25.0)$ & 0.20 \\
\hline \multicolumn{6}{|l|}{ Comorbidities before index date } \\
\hline Alcohol-related disease & 187 & $(3.95)$ & 163 & $(3.44)$ & 0.19 \\
\hline Cardiovascular disease & 1656 & $(34.9)$ & 1677 & $(35.4)$ & 0.65 \\
\hline Chronic kidney disease & 285 & $(6.01)$ & 321 & $(6.77)$ & 0.13 \\
\hline Chronic liver disease & 774 & $(16.3)$ & 786 & $(16.6)$ & 0.74 \\
\hline Chronic obstructive pulmonary disease & 727 & $(15.3)$ & 756 & $(16.0)$ & 0.41 \\
\hline Colorectal adenoma & 748 & $(15.8)$ & 735 & $(15.5)$ & 0.71 \\
\hline Diabetes mellitus & 652 & $(13.8)$ & 685 & $(14.5)$ & 0.33 \\
\hline Hyperlipidemia & 1392 & $(29.4)$ & 1416 & $(29.9)$ & 0.59 \\
\hline Hypertension & 2403 & $(50.7)$ & 2429 & $(51.3)$ & 0.59 \\
\hline Inflammatory bowel disease & 84 & $(1.77)$ & 53 & $(1.12)$ & 0.01 \\
\hline
\end{tabular}

Data are presented as the number of subjects in each group with percentages given in parentheses.

${ }^{*}$ Chi-square test and ${ }^{\dagger} t$-test comparing cases with colorectal cancer and matched controls

\begin{tabular}{|c|c|c|c|c|}
\hline \multirow[b]{2}{*}{ Variable } & \multicolumn{2}{|c|}{ Crude } & \multicolumn{2}{|c|}{ Adjusted $^{\dagger}$} \\
\hline & OR & $(95 \% \mathrm{Cl})$ & OR & $(95 \% \mathrm{Cl})$ \\
\hline $\begin{array}{l}\text { Ever use of selective serotonin reuptake inhibitors (never use as a } \\
\text { reference) }\end{array}$ & 0.78 & $(0.67,0.90)$ & 0.77 & $(0.66,0.89)$ \\
\hline
\end{tabular}

${ }^{\dagger}$ Variables which were found to be significantly associated with colorectal cancer in a univariable logistic regression model were further included in a multivariable logistic regression model. Adjusting for sex and inflammatory bowel disease

\begin{tabular}{|c|c|c|c|c|c|}
\hline Variable & $\begin{array}{l}\text { Case number I } \\
\text { control number }\end{array}$ & $\begin{array}{c}\text { Crude } \\
\text { OR }\end{array}$ & $(95 \% \mathrm{Cl})$ & $\begin{array}{c}\text { Adjusted } \\
\mathrm{OR}^{\dagger}\end{array}$ & $(95 \% \mathrm{Cl})$ \\
\hline $\begin{array}{l}\begin{array}{c}\text { Never use of selective serotonin reuptake inhibitors as a } \\
\text { reference }\end{array}\end{array}$ & $4417 / 4332$ & 1.00 & (reference) & 1.00 & (reference) \\
\hline \multicolumn{6}{|l|}{$\begin{array}{l}\text { Cumulative duration of selective serotonin reuptake } \\
\text { inhibitors use }\end{array}$} \\
\hline$<12$ months & $261 / 318$ & 0.81 & $(0.68,0.95)$ & 0.80 & $(0.67,0.95)$ \\
\hline$\geq 12$ months & $61 / 89$ & 0.67 & $(0.48,0.93)$ & 0.66 & $(0.47,0.92)$ \\
\hline
\end{tabular}

†Variables which were found to be significantly associated with colorectal cancer in a univariable logistic regression model were further included in a multivariable logistic regression model. Adjusting for sex and inflammatory bowel disease 
cases with colorectal cancer were lower than among matched controls (adjusted OR 0.66; 95\% CI 0.47-0.92).

\section{DISCUSSION}

We observed that the odds of selective serotonin reuptake inhibitors use among cases with colorectal cancer were lower than among matched controls (adjusted OR 0.77 , Table 2). This finding was statistically significant and indicated that selective serotonin reuptake inhibitors use might be a protective factor against colorectal cancer, which was compatible with previous epidemiologic studies showing that selective serotonin reuptake inhibitors use was associated with $30 \%-53 \%$ risk reduction of colorectal cancer., ${ }^{5,6}$ We observed that there was a durationdependent effect of selective serotonin reuptake inhibitors use on the risk of colorectal cancer (Table 3). That is, the longer the selective serotonin reuptake inhibitors use, the lower the risk of colorectal cancer.

The underlying pathogenesis between selective serotonin reuptake inhibitors use and colorectal cancer cannot be clarified in this observational study. The current evidence indicates that selective serotonin reuptake inhibitors possess potential anti-proliferative effects on tumor cells and further inhibit the growth of colorectal tumor. ${ }^{3,4,24}$

Some limitations should be mentioned. First, due to the limitation of a case-control study, the causal relationship cannot be determined. A prospective clinical trial or other real-world data are required to examine whether selective serotonin reuptake inhibitors can be used for chemoprevention of colorectal cancer. Second, due to the natural limitation of claims data, body mass index was not recorded in the database. We could not include obesity for analysis.

\section{CONCLUSION}

We conclude that the odds of selective serotonin reuptake inhibitors use among cases with colorectal cancer are lower than among matched controls. This finding supports the evidence from previous animal and epidemiologic studies that selective serotonin reuptake inhibitors use might be a protective factor against colorectal cancer. In addition, the protective effect for colorectal cancer is stronger for longer cumulative duration of selective serotonin reuptake inhibitors use.

\section{ACKNOWLEDGEMENT}

This study was supported in part by the Ministry of Health and Welfare, Taiwan (MOHW108-TDUB-212-133004) and China Medical University Hospital,
Taiwan (DMR-107-192). These funding agencies did not influence the study design, data collection and analysis, decision to publish, or preparation of the manuscript.

\section{Specific author contributions}

Shih-Wei Lai contributed to the conception of the article, initiated the draft of the Article and revised the article.

Cheng-Li Lin and Kuan-Fu Liao conducted data analysis.

\section{CONFLICT OF INTEREST}

The authors declare no conflict of interest.

\section{ETHICAL STATEMENT}

Insurance reimbursement claims data used in this study were available for public access. Patient identification numbers were scrambled to ensure confidentiality. Patient informed consent was not required. This study was approved by the Research Ethics Committee of China Medical University and Hospital in Taiwan (CMUH-104-REC2-115).

\section{SUMMARY}

The odds of selective serotonin reuptake inhibitors use among cases with colorectal cancer are lower than among matched controls. This finding indicates that selective serotonin reuptake inhibitors use might be a protective factor against colorectal cancer.

\section{REFERENCES}

1. Mace S, Taylor D. Selective serotonin reuptake inhibitors: a review of efficacy and tolerability in depression. Expert Opin Pharmacother. 2000;1(5):917-33.

2. Usala T, Clavenna A, Zuddas A, Bonati M. Randomised controlled trials of selective serotonin reuptake inhibitors in treating depression in children and adolescents: a systematic review and meta-analysis. Eur Neuropsychopharmacol. 2008;18(1):62-73.

3. Kannen V, Marini T, Turatti A, et al. Fluoxetine induces preventive and complex effects against colon cancer development in epithelial and stromal areas in rats. Toxicol Lett. 2011;204(2-3):134-40.

4. Gil-Ad I, Zolokov A, Lomnitski L, et al. Evaluation of the potential anti-cancer activity of the antidepressant sertraline in human colon cancer cell lines and in colorectal cancer-xenografted mice. Int J Oncol. 2008;33(2):277-86.

5. Xu W, Tamim H, Shapiro S, Stang MR, Collet JP. Use of antidepressants and risk of colorectal cancer: a nested case-control study. Lancet Oncol. 2006;7(4):301-8.

6. Coogan PF, Strom BL, Rosenberg L. Antidepressant use and colorectal cancer risk. Pharmacoepidemiol Drug Saf. 2009;18(11):1111-4.

7. Chubak J, Boudreau DM, Rulyak SJ, Mandelson MT. Colorectal cancer risk in relation to antidepressant medication use. Int J Cancer. 2011;128(1):227-32.

8. Lee HC, Chiu WC, Wang TN, et al. Antidepressants and colorectal cancer. A population-based nested case-control study. J Affect Disord. 2017;207:353-8.

9. Cronin-Fenton DP, Riis AH, Lash TL, et al. Antidepressant use and colorectal cancer risk: a Danish population-based case-control study. $\mathrm{Br} \mathrm{J}$ Cancer. 2011;104(1):188-92. 
10. Lee HK, Eom CS, Kwon YM, Ahn JS, Kim S, Park SM. Meta-analysis: selective serotonin reuptake inhibitors and colon cancer. Eur J Gastroenterol Hepatol. 2012;24(10):1153-7.

11. Ministry of Health and Welfare Taiwan. 2016 statistics of causes of death http://www.mohw.gov.tw/EN/Ministry/Index.aspx [cited on July 1, 2017, English version].

12. Ministry of Health and Welfare Taiwan. 2016 Taiwan Health and Welfare Report. http://www.mohw.gov.tw [cited on July 1, 2017, English version].

13. Liao KF, Huang PT, Lin CC, Lin CL, Lai SW. Fluvastatin use and risk of acute pancreatitis:a population-based case-control study in Taiwan. BiomedicineTaiwan 2017;7(3):24-8

14. Lai SW, Lin CL, Liao KF. Association between oral corticosteroid use and pyogenic liver abscesses in a case-control study. Biomedicine. 2018;8(1):33-9.

15. Lai SW, Liao KF, Liao CC, Muo CH, Liu CS, Sung FC. Polypharmacy correlates with increased risk for hip fracture in the elderly: a populationbased study. Medicine. 2010;89(5):295-9.

16. Liao KF, Cheng KC, Lin CL, Lai SW. Etodolac and the risk of acute pancreatitis. Biomedicine-Taiwan. 2017;7(1):25-9.

17. Lin HF, Liao KF, Chang CM, Lin CL, Lai SW. Statin use correlates with reduced risk of chronic osteomyelitis: a nationwide case control study in Taiwan. Current Medical Research and Opinion. 2017;33(12):2235-40.
18. Shen ML, Liao KF, Tsai SM, Lin CL, Lai SW. Herpes zoster correlates with pyogenic liver abscesses in Taiwan. Biomedicine-Taiwan . 2016;6(4):24-9.

19. Lin HF, Liao KF, Chang CM, Lin CL, Lai SW. Tamoxifen usage correlates with increased risk of Parkinson's disease in older women with breast cancer: a case-control study in Taiwan. Eur J Clin Pharmacol. 2018;74(1):99-107.

20. Hung SC, Liao KF, Hung HC, et al. Using proton pump inhibitors correlates with an increased risk of chronic kidney disease: a nationwide databasederived case-controlled study. Fam Pract. 2018;35(2):166-71.

21. Cheng KC, Liao KF, Lin CL, Lai SW. Correlation of Proton Pump Inhibitors with Pulmonary Tuberculosis: A Case-Control Study in Taiwan. Front Pharmacol. 2017;8:481.

22. Lai SW, Cheng KC, Lin CL, Liao KF. Furosemide use and acute risk of hip fracture in older people: A nationwide case-control study in Taiwan. Geriatr Gerontol Int. 2017;17(12):2552-8.

23. Hung SC, Liao KF, Hung HC, Lin CL, Lai SW, Lin $\mathrm{CH}$. Nabumetone use and risk of acute pancreatitis in a case-control study. Pancreatology. 2016;16(3):353-7.

24. Stopper H, Garcia SB, Waaga-Gasser AM, Kannen V. Antidepressant fluoxetine and its potential against colon tumors. World J Gastrointest Oncol. 2014;6(1):11-21.

Cite this article: Lai SW, Lin CL, Liao KF. Association between Selective Serotonin Reuptake Inhibitors use and Colorectal Cancer in a Case-Control Study. Indian J of Pharmaceutical Education and Research. 2019;53(2):325-9. 